\title{
On the Development of Position of the Tooth Germs in the Human Deciduous Front Teeth
}

\author{
By \\ Tadahiro Ooé \\ (Department of Anatomy, Tokyo Medical and Dental University)
}

The central incisor, lateral incisor, and the canine have a tendency to be situated on the labial, lingual, and again on the labial side of the jaw, respectively. This peculiar arrangement of the teeth is especially marked during the embryological stage or the stage when the teeth are still embedded in the jaw bone, as will be seen in fig. 11 and 22.

This fact seems to have been interpreted as being due to the circumstance that at this stage of growth the tooth germs or the completed crowns are relatively too large for the jaw bones to receive them. In other words the lack of space is responsible for the zigzag arrangement of the tooth germs. But in my opinion this alone can not explain the reason why in every case the central incisor and the canine are derailed to the labial side, and the lateral incisor to the lingual side. In spite of the number of papers on the development of the teeth, the above problem is not yet satisfactorily solved.

So the main purpose of the this research work has been to give a clear explanation to this interesting problem. I payed special attention to the mode of development of the tooth germs and their topographical relation to each other.

\section{Materials and Method}

The materials studied were exclusively human embryos. For fixation formalin was used. After photographing the external aspect of the body, the embryos were embedded in celloidin. Sections cut serial-

This research work was assigned to me by Dr. T. Fujita, Professor of Anatomy, Tokyo University Medical School, when I was an assistant there. Thanks are due to him for his resourceful suggestions and kind guidance in this investigation. 
List of material

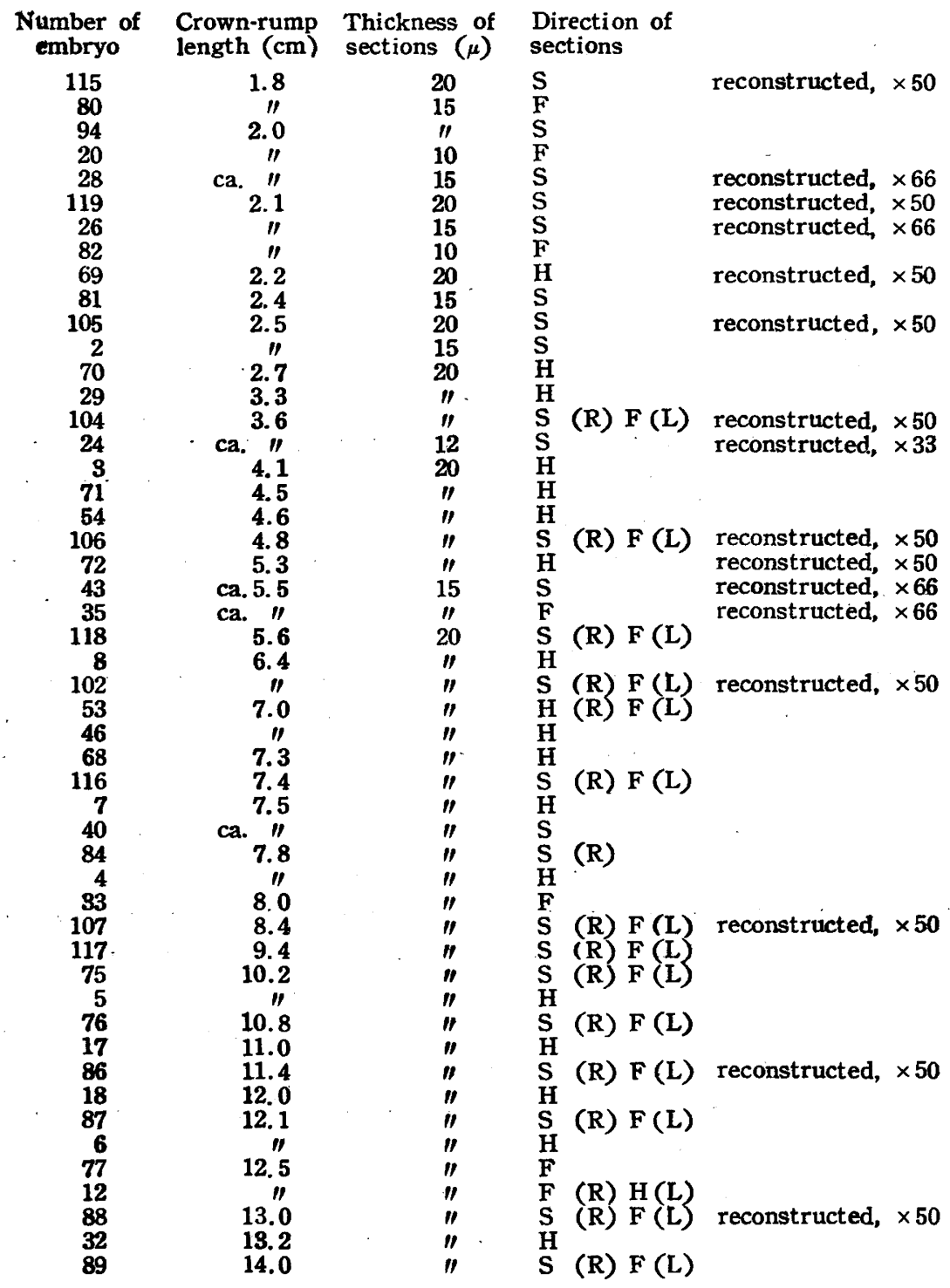

Note: S: sagittal, F : frontal, $\mathrm{H}$ : horizontal section, $\mathrm{R}$ : right side, L: left side.

ly in sagittal, frontal or horizontal directions were stained with hematoxylin-eosin. For exact orientation and convenient explanation many reconstruction models were made. For the study of morphological changes of the front tooth germs, it is convenient to use the sagit- 
tal sections, as most of the previous. investigators did, but for the purpose of my observations, i. e., to pursue the changes of their position and orientation it is rather advantageous to use the horizontal sections.

As, in the present investigation, the aim was to get an exact idea about the earlier stage of tooth development, observation was confined to the germs in the bud stage up to during the period of beginning calcification. So the materials ranged from the embryos of about one and one-half months to those at the end of five months. Below will be listed the specimen number, direction of sections, their thickness, and the magnification of the reconstructions.

In reseach works of this kind, it is essential to prepare reconstruction models in an accurate way. So I was exceedingly careful to keep the orientation marks of the blocks perpendicular to the cut surface of the microtome. It goes without saying that any disproportionate contraction or distortion of the sections should absolutely be avoided.

There are several types of orientation marks devised by previous investigators. In this investigation I used a plastic plate with a small perpendicular hole. This plate was placed on the cut surface of the block, and the block was pierced with a thin needle through the hole. In this way, exact perpendicular inducement of the needle was secured, and by moving the plate the orientation marks could be made at any place desired.

As model plates cardboard paper was used instead of wax plates. In laying the boards upon each other, in addition to the orientation marks accuracy was aimed for by examining, under high power magnification of microscope, the inclination of the boundary of the epithelium and mesoderm of the sections.

The figures were drawn with my own hand. Except for fig. 6 and 17, they are drawn as viewed from the side of mesoderm, or from the bottom of the enamel organs. From the consideration of giving a better idea as to the shape of the oral cavity and the position of the tooth germs, the area of the models is extended as far as possible.

\section{Observations of the lower jaw}

Fig. 1 shows the reconstruction model of specimen No. 119 (2.1 $\mathrm{cm}$ ). The bilateral diameter of the oral cavity, posteriorly to the mouth opening, is slightly increased in length, as compared with the prior stage, a sign of the cheek formation. The lower lip is seen as a slight depression in a flat arch form, the medial portion of which 


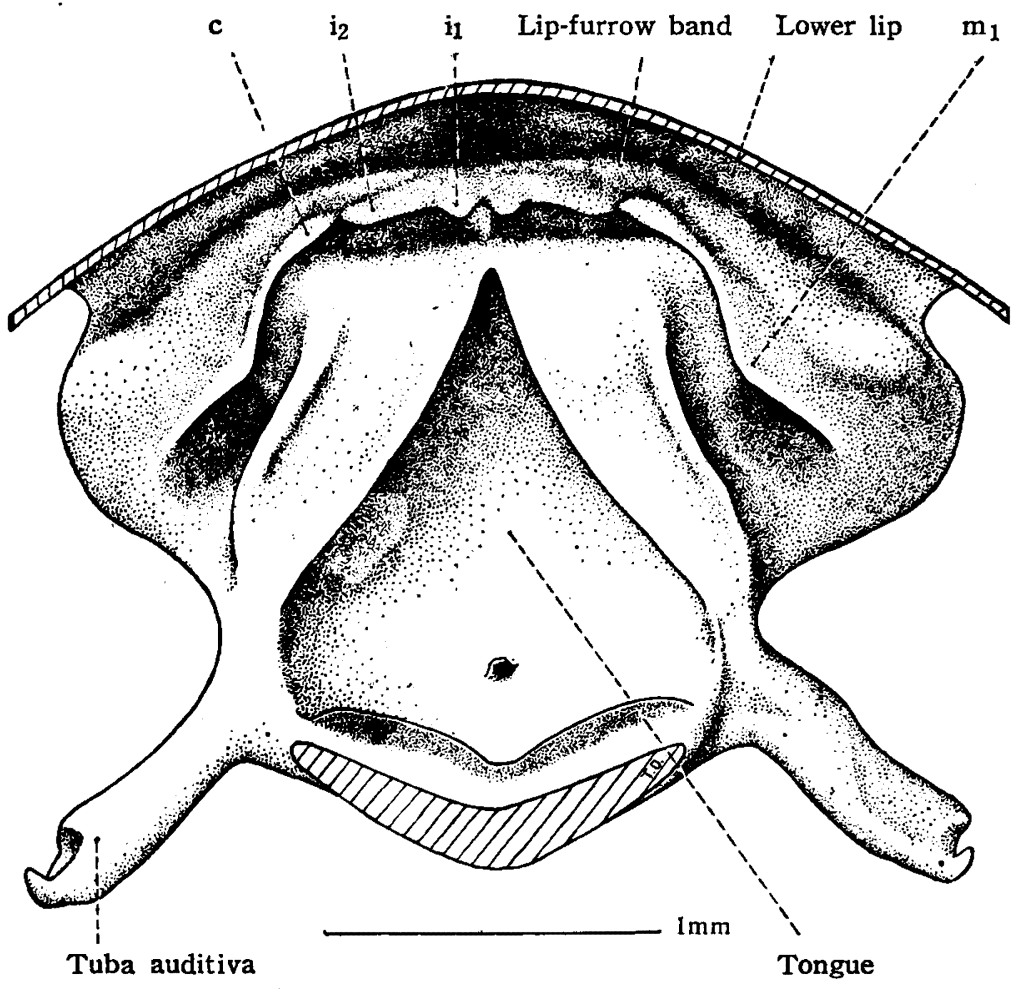

Fig. 1. $119(2.1 \mathrm{~cm})$ Reconstruction.

is, however, deeper than the lateral portions. Bordering this from behind is the vestibule. The dental lamina is already markedly elevated from the level of the oral epithelium. Corresponding to the germs of $i_{1}, i_{2}, c$ and $m_{1}$ of both sides eight nodes are projecting from the dental lamina so that the free margin of the lamina shows a wavy contour. In the region of the front teeth the vestibule is located close to the dental lamina in the form of a lip-furrow band and in the posterior region it makes the contour of the oral cavity somewhat widely separated from the dental lamina.

The dental lamina shows a characteristic feature in the direction of the ingrowth of the tooth germs; the anlage of the central incisor runs horizontaly in the lingual direction, while the lateral incisor has a similar orientation but its free margin is gently sloped toward the central incisor and steeply curved toward the canine. Above all it should be noticed that the canine germ shows already the tendency of derailing to the labial side. Far distal to the canine there is the 
indication of the first deciduous molar tooth.

In order to give the numerical data regarding the position of the tooth germs to each other, measurement was carried out on the models. Taking the tip of the nodes for the points of measurement, the following figures were obtained: distance between $i_{1}$ and $i_{2}, 0.32 ; i_{2}$ and $c$, 0.2 ; $c$ and $\mathrm{m}_{1}, 0.56$ (unit in $\mathrm{mm}$ ). Here we see distinctly that the distance between the canine and the first deciduous molar tooth is the largest, and that between the canine and the lateral incisor is very small, while the central incisors of both sides are located near each other most closely. The close position of the canine to the lateral incisor together with the deep notch between them is characteristic of the lower jaw. But, later the distance grows and surpasses that between the central and the lateral incisors (fig. 8).

In regard to the vertical relationship, the canine germ is situated the deepest, or in other words it is situated utmost downwards. This is because the ingrowth of the canine is directed more to the labial side than the incisors and also because the oral epithelium is originally situated deep at the level of the canine germ.

In fig. 2 is shown the ingrowth of the incisors and the canine on the sagittal sections. As the photopraphs were taken with the orienta-
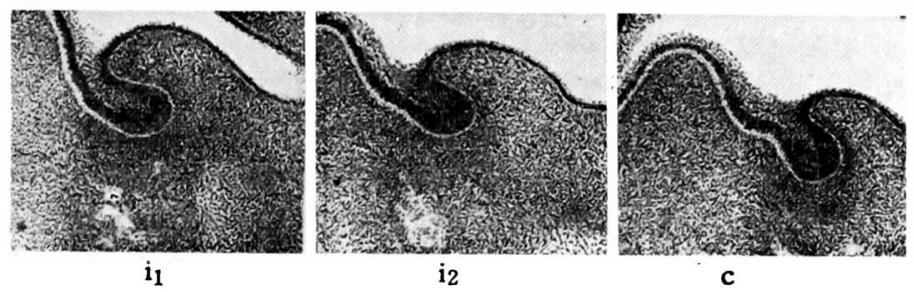

Fig. 2. No. $119(2.1 \mathrm{~cm})$ Sagittal section. $\times 60$

tion marks placed on the same spot of the optical field, they might be regarded as having been taken without moving the position of the camera or the eye. Therefore the difference in the position of the tooth germs and in the direction of their ingrowth seen in the photographs can be considered to be the difference in the natural relative relationship projected on the sagittal plane.

By comparing the photographs, it is obvious that the incisor germs are directed to the right in the figures, i. e., toward the tongue in the body, while the canine germ is extending more downward. At the same time notice the deeper situation of the canine with its adjacent oral epithelium. 
Also in the other specimens of the same stage, similar conditions were observed. The frontal sections showed especially well the fact that the central incisor is directed backward, because in the posterior sections the germ was isolated from the dental lamina just like an island. The examination of the horizontal section was also instructive and gave a good orientation especially as to the deep standing of the canine. In fig. 3 is shown the horizontal section of the lower jaw at

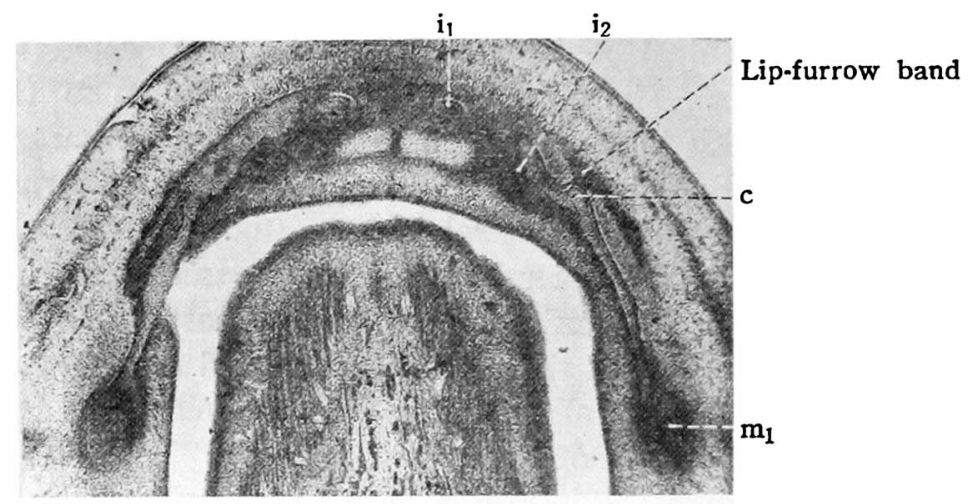

Fig. 3. No. $69(2.2 \mathrm{~cm})$ Horizontal section. $\times 28$

the level of the lateral incisor germ. On the right side the canine germ has already disappeared, the spot of its connection with the dental lamina is indicated by $\mathrm{c}$, while the central incisor is represented by an insular areola of the epithelium which corresponds to the inferior surface of the germ. In addition, this section shows clearly that the distance between the lateral incisor and the canine is still shorter than that between the central and the lateral incisors as well as that between the canine and the first deciduous molar tooth.

Fig. 4 shows the model of secimen No. $105(2.5 \mathrm{~cm})$, a little more advanced stage of development. The tooth germs are developed the canine being especially marked. Except for the expansion of the tooth germs the model is exactly the same as in fig. 1. By actual measurement the distance between the germs is; $i_{1}$ and $i_{2}, 0.4,0.46 ; i_{2}$ and $c$, $0.28,0.28 ; \mathrm{c}$ and $\dot{\mathrm{m}}_{1}, 0.76,0.72$ (unit in $\mathrm{mm}$; the figures written first are for the right side and the latter for the left side). So the relationship of position of the germs as observed in fig. 1 is still maintained in this model.

On model No. $104(3.6 \mathrm{~cm})$ it was cofirmed that the epithelium on the labial surface of the tooth germs proliferates and is elevated from the dental lamina. The central incisor was of a dish shape. 


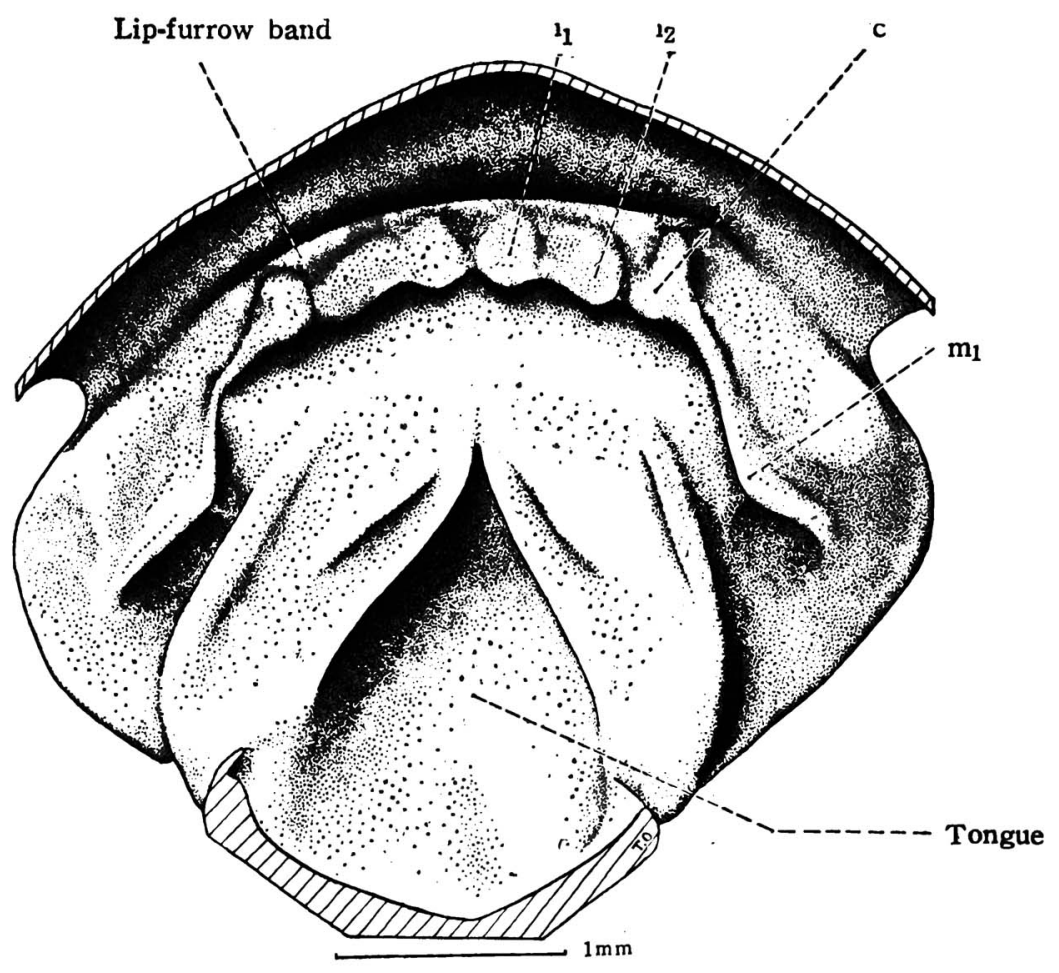

Fig. 4. No. $105(2.5 \mathrm{~cm})$ Reconstruction.

The epithelial proliferation of the lateral incisor was more marked than that of the central incisor and as it occurred in the distal as well as in the lingual direction this tooth germ became to be situated somewhat obliquely. The epithelial projection of the canine was extending in the labial as well as in the distal direction. There developed the enamel niche opening distally and the dental papilla facing labially and downward.

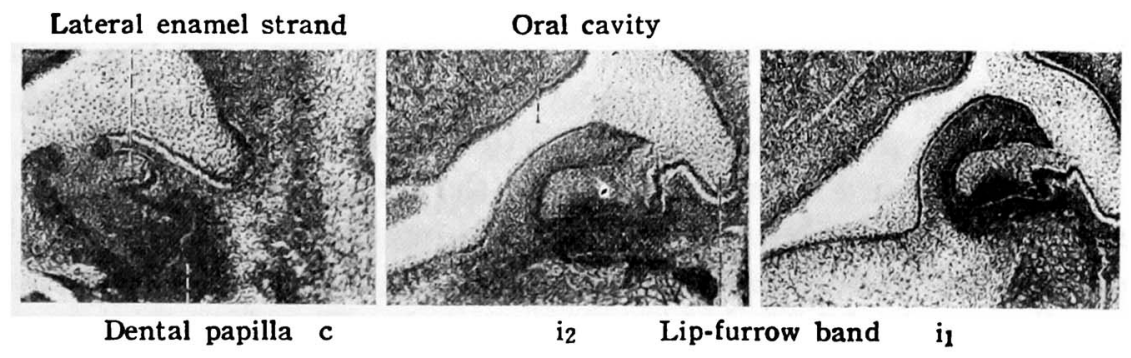

Fig. 5. No. $104(3.6 \mathrm{~cm})$ Sagittal section. $\times 54$ 
Fig. 5 are photographs of the sagittal sections of No. $104(3.6 \mathrm{~cm})$ taken in the same way as fig. 2. Note that the enamel organs of the central and the lateral incisors are facing downward while that of the canine faces obliquely labially and downward. That the canine is situated the deepest and the lateral and the central incisors follow it in this order, an important positional relationship observed already in fig. 2 , has become still more evident in this stage of development.

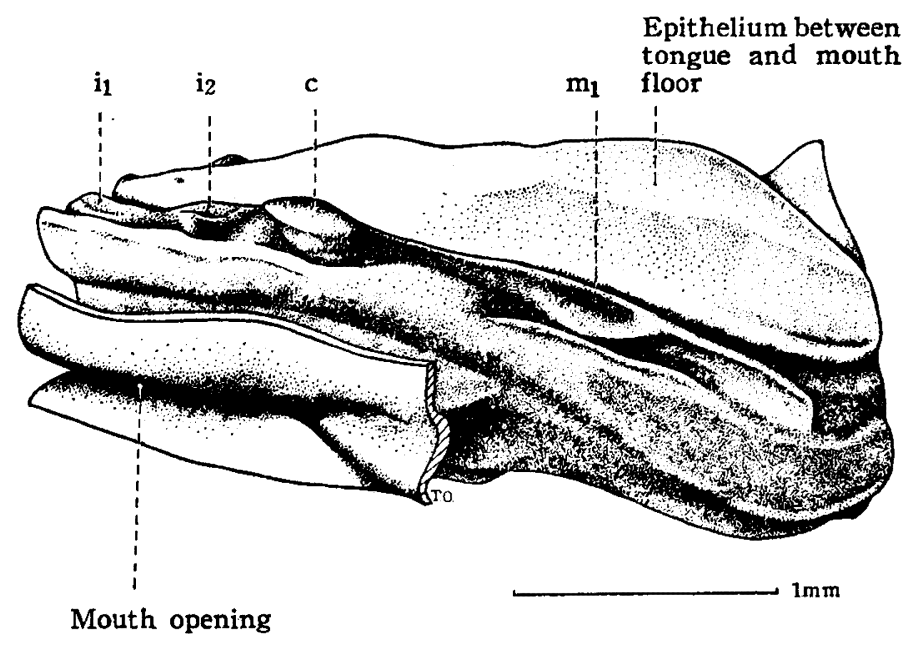

Fig. 6. No. $104(3.6 \mathrm{~cm})$ Reconstruction.

Fig. 6 shows the anterolateral view of the model of specimen No. $104(3.6 \mathrm{~cm})$. Here we see again that the canine is situated deep in the jaw and extending in the labial direction, while the lateral and the central incisors are located more superficially in reference to the oral cavity.

In fig. 7 which shows the right half of model No. $106(4.8 \mathrm{~cm})$, the epithelial projection of the tooth germs on the labial side is remarkable and they are strikingly protruding from the dental lamina. Owing to the unequal growth of the epithelial tooth germs, the niche is now formed in the canine and the lateral incisor. As the canine expands in the labial direction and the growth of its epithelial projection is the most marked among the three front teeth, the niche is most advanced in development. Thus, the peculiar arrangement that the central incisor is on the labial side and the distal end of the lateral incisor extends in the lingual direction and the canine is again protruding to the labial side has just started. The distance between the tooth germs is; $i_{1}$ and $i_{2}, 0.66 \mathrm{~mm} ; i_{2}$ and $c, 0.56 \mathrm{~mm} ; c$ and $\mathrm{m}_{1}$, 


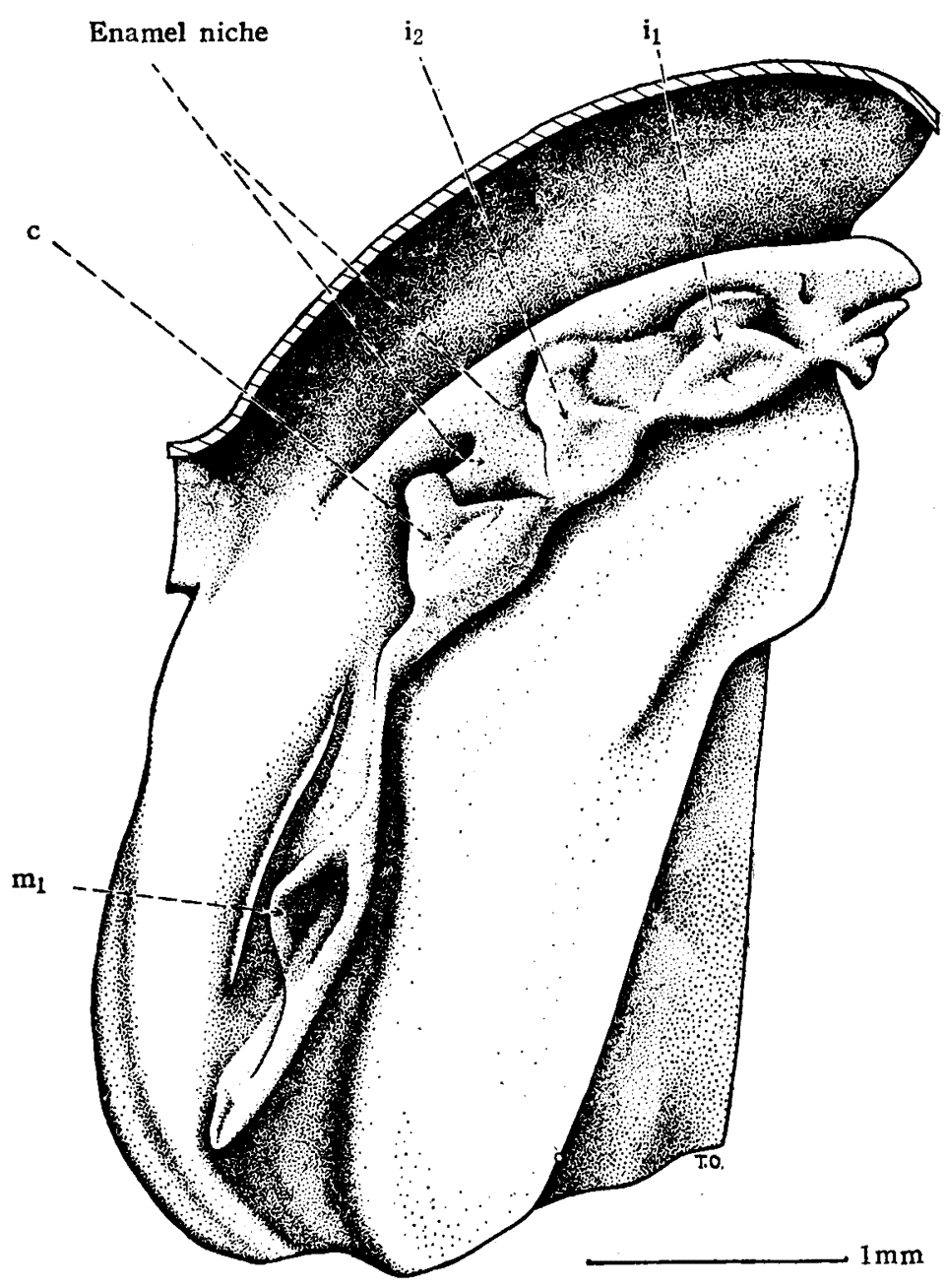

Fig. 7. No. $106(4.8 \mathrm{~cm})$ Reconstruction.

$1.36 \mathrm{~mm}$, the distance between the canine and the lateral incisor still being the shortest.

In the following stage, the enamel organ of the canine which has been facing the labial side shows now a tendency to turn downwards. Its distance from the lateral incisor becomes longer than that between the central and the lateral incisors.

In fig. 8, model of the right side of embryo, No $102(6.4 \mathrm{~cm})$, the germs have progressed much in their development. The lateral enamel strand of the central incisor runs toward the mesial side while that of the lateral incisor obliquely toward the mesiolabial side. The enamel 


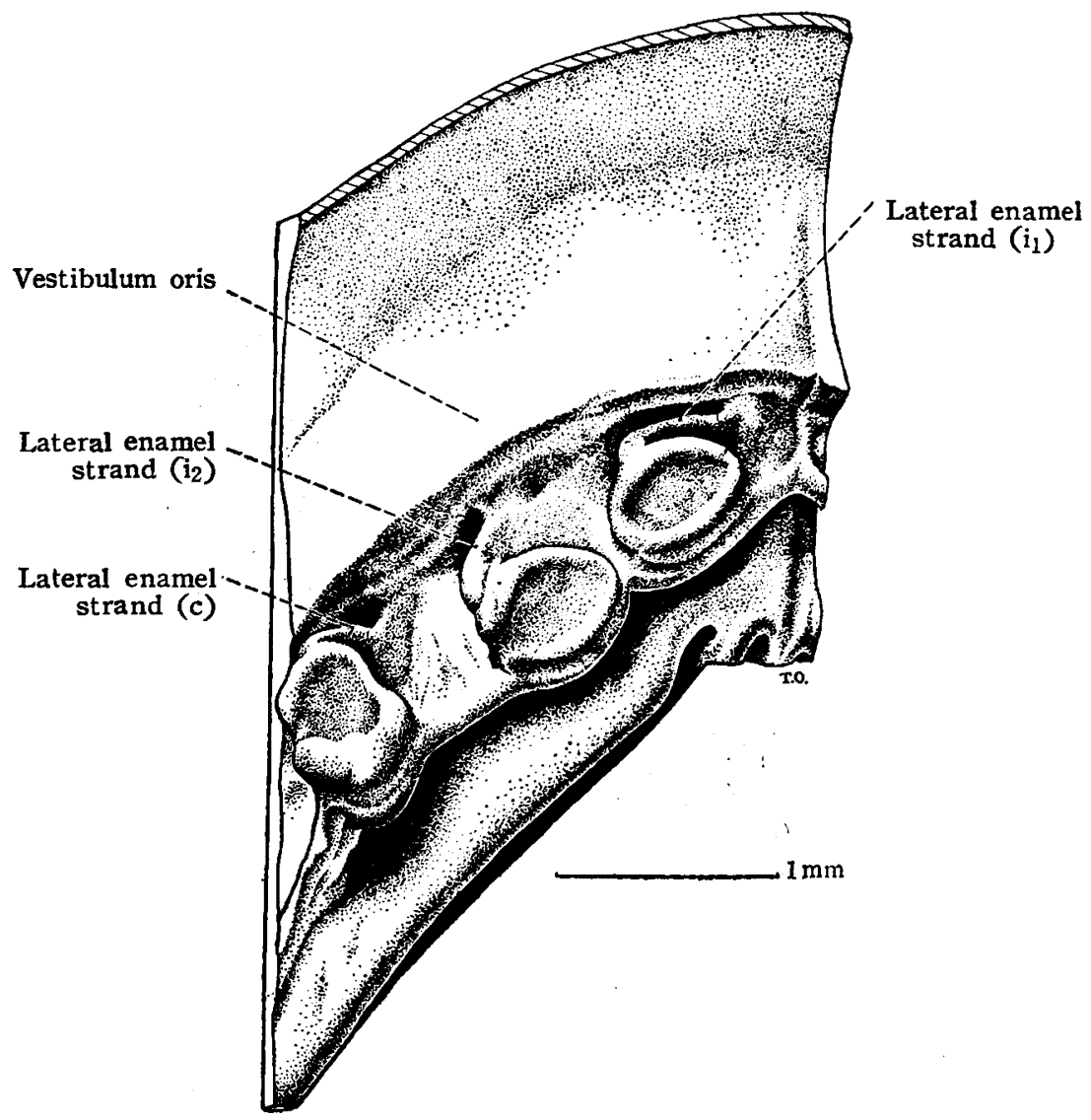

Fig. 8. No. $102(6.4 \mathrm{~cm})$ Reconstruction.

organ of the lateral incisor is therefore so located that the prospective distal end is directed somewhat to the lingual side. The enamel strand of the canine extends again mesially with the enamel organ facing labially and at the same time downwards. Furthermore the zigzag arrangement of the three germs is quite evident in the figure.

As regards the vertical position, the canine germ is situated the deepest and the central incisor most superficially. The distance between the germs being; $i_{1}$ and $i_{2}, 0.72 \mathrm{~mm} ; i_{2}$ and $c, 0.98 \mathrm{~mm}$, the interspace between the central and the lateral incisors becoming shorter than that between the lateral incisor and the canine.

Fig. 9 represents the model of the right front teeth of embryo No. $107(8.4 \mathrm{~cm})$. The so-called permanent dental lamina, the indication of which was already noticeable in fig. 8 , is more distinctly projected 


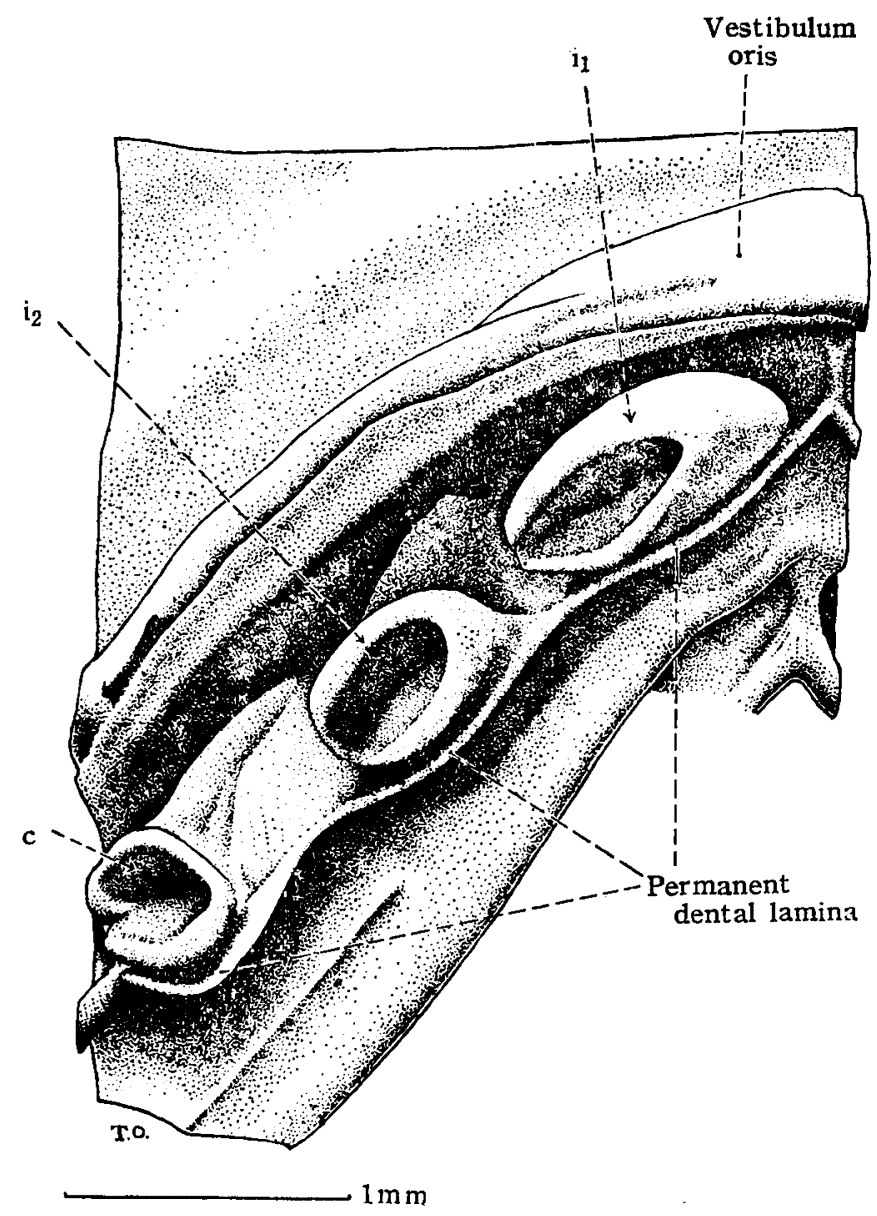

Fig. 9. No. $107(8.4 \mathrm{~cm})$ Reconstruction.

in a tongue shape on the lingual side of the deciduous set of teeth. The central incisor is placed along the prospective dental arch, while the lateral incisor shows a slight but distinct rotation with its distal extremity turning inward. The enamel organ of canine, which is still relatively small and round, is slightly leaning toward the labial side. Note that also in this stage of development, in which there is still ample interspace between the adjacent enamel organs, the zigzag arrangement of the germs is distinct. The distance between the tooth germs is : $i_{1}$ and $i_{2}, 1.0 \mathrm{~mm} ; i_{2}$ and $c, 1.12 \mathrm{~mm}$, the distance between the central and the lateral incisors being the shortest.

In fig. 10 , model of embryo No. $86(11.4 \mathrm{~cm})$, the development is 


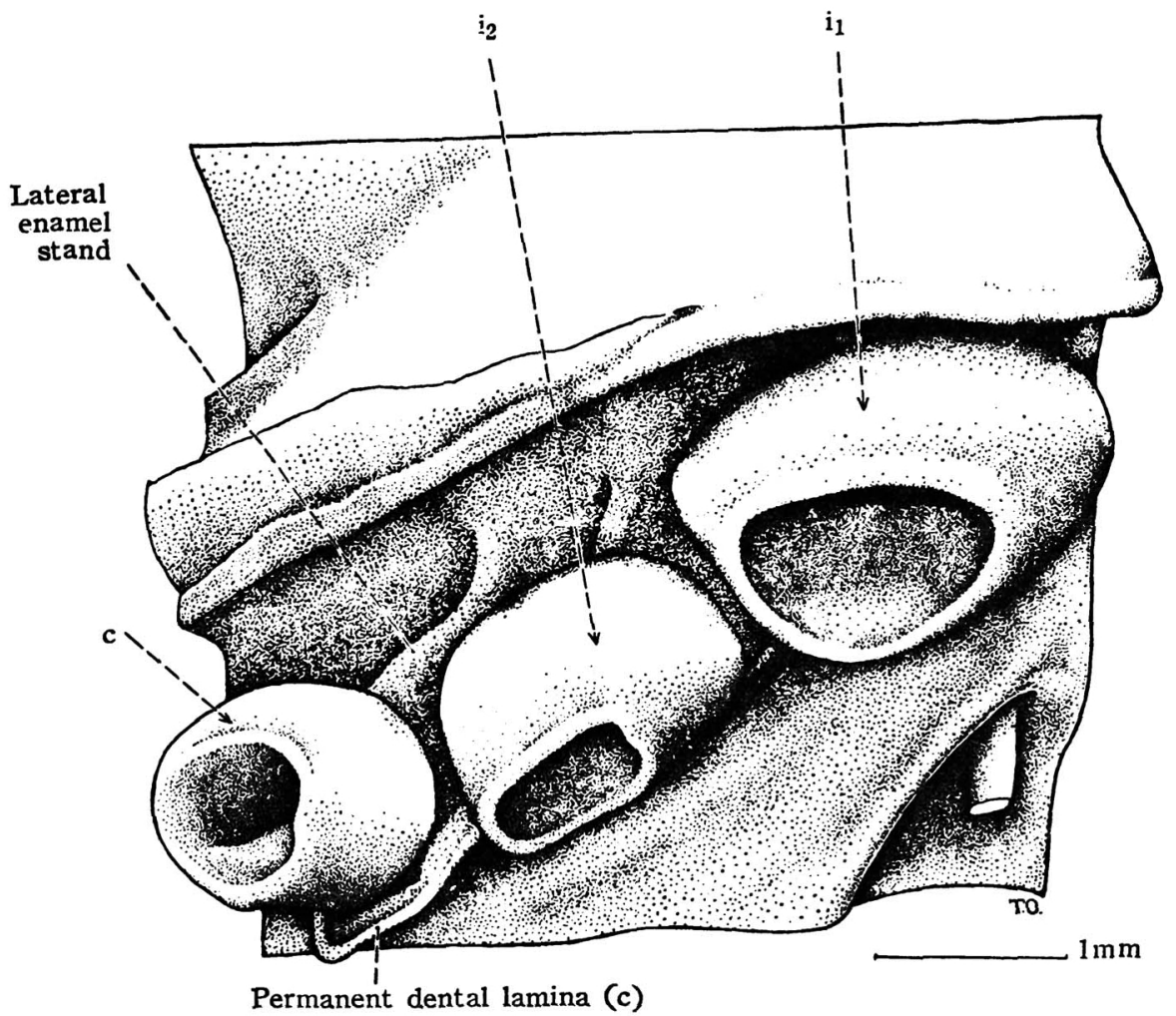

Fig. 10. No. $86(11.4 \mathrm{~cm})$ Reconstruction.

so advanced that the calcification has begun in the central and the lateral incisors. Accordingly the tooth germs, especially that of the central incisor, have grown remarkably and their alternating labial, lingual, and again the labial positions are so much more distinct. The interspace between the germs is still existing. The permanent

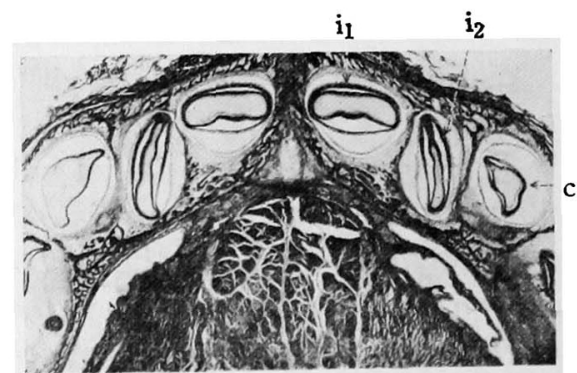

Fig. 11. No. $62(28 \mathrm{~cm})$ Horizontal section. $\times 3$ dental lamina, which can be seen in the figure only in the canine region, is distinctly isolated from the milk tooth germ. The distance between the centre of the tooth germs by actual measurement is : $i_{1}$ and $\mathrm{i}_{2}, 1.8 \mathrm{~mm} ; \mathrm{i}_{2}$ and $\mathrm{c}, 1.4 \mathrm{~mm}$, the $i_{2}$ and $c$ distance being shorter, but this is due to the central and the lateral incisors 
being large and the canine small, the interspace itself being greater between $i_{2}$ and $c$ than between $i_{1}$ and $i_{2}$.

Fig. 11 is the photograph of a horizontal section of the lower jaw of embryo No. $62(28.0 \mathrm{~cm})$, illustrating the peculiar orientation of the front teeth in the jaw. The central incisors are situated labially with their major axis of the section placed almost in the frontal direction, while the lateral incisors are so strongly rotated that their axis stands nearly vertical to that of the central incisors and very much derailed inward from the $\mathrm{i}_{1}-\mathrm{c}$ line. The canine again is projecting to the labial side, with some grade of rotation in the sense as the lateral incisors.

\section{Observations of the upper jaw}

Also in the upper jaw the tooth germs show their characteristic types of ingrowth of the epithelium already in the bud stage.

In fig. 12, embryo No. $119(2.1 \mathrm{~cm})$, the central incisor is broad but has a low semispherical shape, and the lateral incisor extends deeply in the palatine direction. Distally to the lateral incisor, the dental lamina bends out labially, so that the canine is directed more

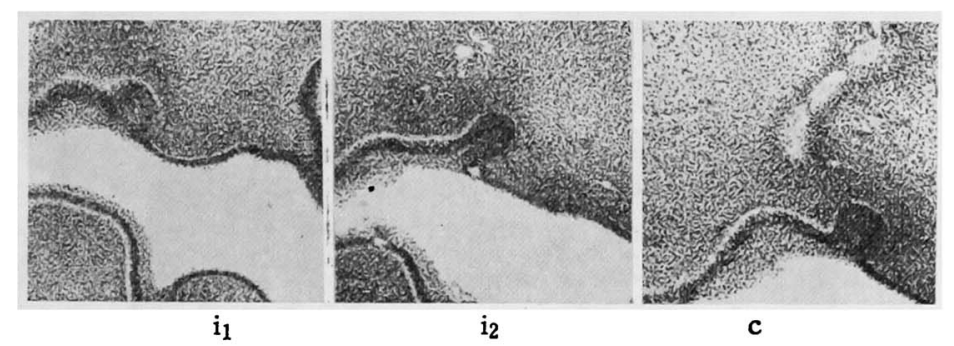

Fig. 12. No. $119(2.1 \mathrm{~cm})$ Sagittal section. $\times 60$

labialward than the incisors. Therefore, also in the upper jaw the tooth germs are arranged in a zigzag line already from the beginning. And the oral cavity has an incisure between the right and left medial nasal processes, the median part of the oral cavity being elevated, and for this reason it is clear that the central incisor is in the highest position and the canine the lowest. The relationship is reverse to that in the lower jaw where the canine is situated the lowest.

In the horizontal sections, if we scan them serially in the vertical direction, the peculiar position of the tooth buds is recognizable (fig. 13). The lateral incisor is situated lingually and the canine labially 


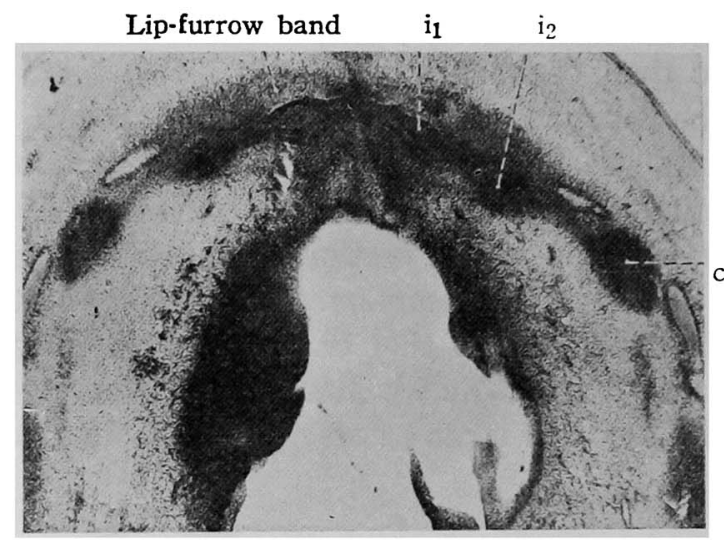

Fig. 13. No. $69(2.2 \mathrm{~cm})$ Horizontal section. $\times 28$

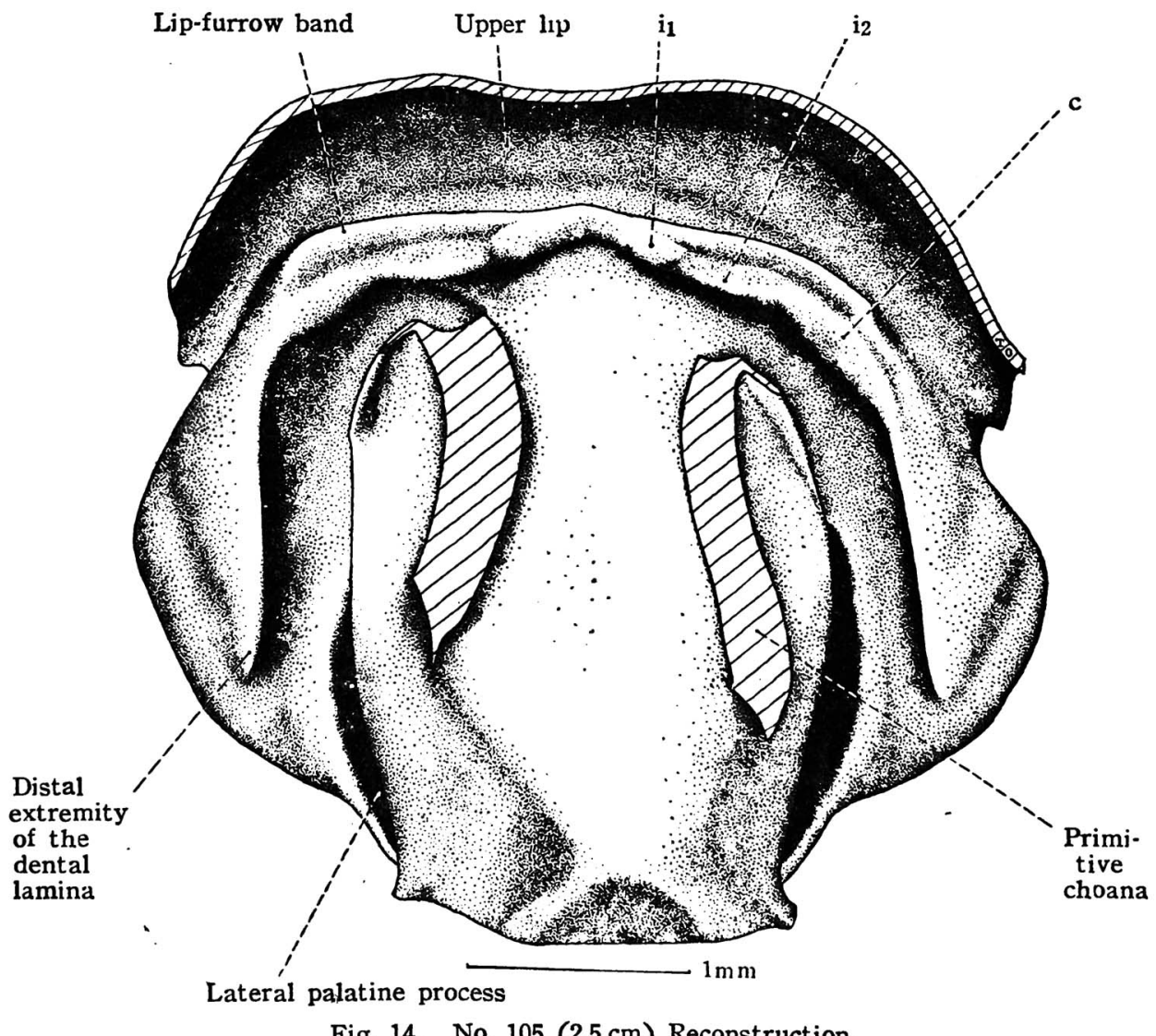

Fig. 14. No. $105(2.5 \mathrm{~cm})$ Reconstruction. 
showing the characteristic arrangement of the upper tooth germs. The distance between the germs is the smallest between the central and the lateral incisors and the largest between the canine and the first deciduous molar tooth.

Fig. 14 shows the model of embryo No. $105 \cdot(2.5 \mathrm{~cm})$. In this model the upper lip is represented as a depression of a flat arch shape and the part forming the boundary behind it is the vestibule. The vestibule appears as the lip-furrow band in the region of the front teeth and is close to the dental lamina, while in the molar region it is present as a depression of the epithelium itself, being widely separated from the dental lamina.

The dental lamina does not run in a smooth curve. The anlage of $i_{1}$ and $c$ is projecting toward the labial side, while that of $i_{2}$ retreats backwards.

The distance between the tooth germs, i. e., between the most projected points of the epithelial anlages, measured: $i_{1}$ and $i_{2}, 0.38$, $0.32 ; \mathrm{i}_{2}$ and $\mathrm{c}, 0.48,0.52 ; \mathrm{c}$ and $\mathrm{m}_{1}, 1.14,1.14 \mathrm{~mm}$, the first figures being for the right and the second for the left side. So, different from the condition of the lower jaw, the distance becomes smaller as one proceeds mesially.

Fig. 15 is the model of the right side of embryo No. $104(3.6 \mathrm{~cm})$. The right and left palatine processes are already fused together and a definitive palate is formed. In the central incisor the epithelium is projected markedly into the deep part of the labial side. The lateral incisor does not yet show this kind of epithelial outgrowth, while the canine germ is markedly thickened and protrudes on its labial surface. The central incisor and the canine give, therefore, an impression as if they were situated labially, and the lateral incisor is rather pushed toward the palatinal side.

The distance between the tooth germs by measuring their centres is : $i_{1}$ and $i_{2}, 0.48 \mathrm{~mm} ; i_{2}$ and c, $0.94 \mathrm{~mm}$, showing no relative changes from the foregoing stages. On the lateral and front aspect, i.e., by projection on a vertical plane, the canine was situated the lowest and the central incisor the highest before, but now in this model this mutual position has changed and the canine stands higher than the incisors.

Fig. 16, photographs of the sagittal sections of a $3.6 \mathrm{~cm}$ embryo, will show very clearly the different levels as well as the different directions of the ingrowth of the front teeth germs.

The fig. 17, the model of No. $106(4.8 \mathrm{~cm})$, the epithelial outgrowth 


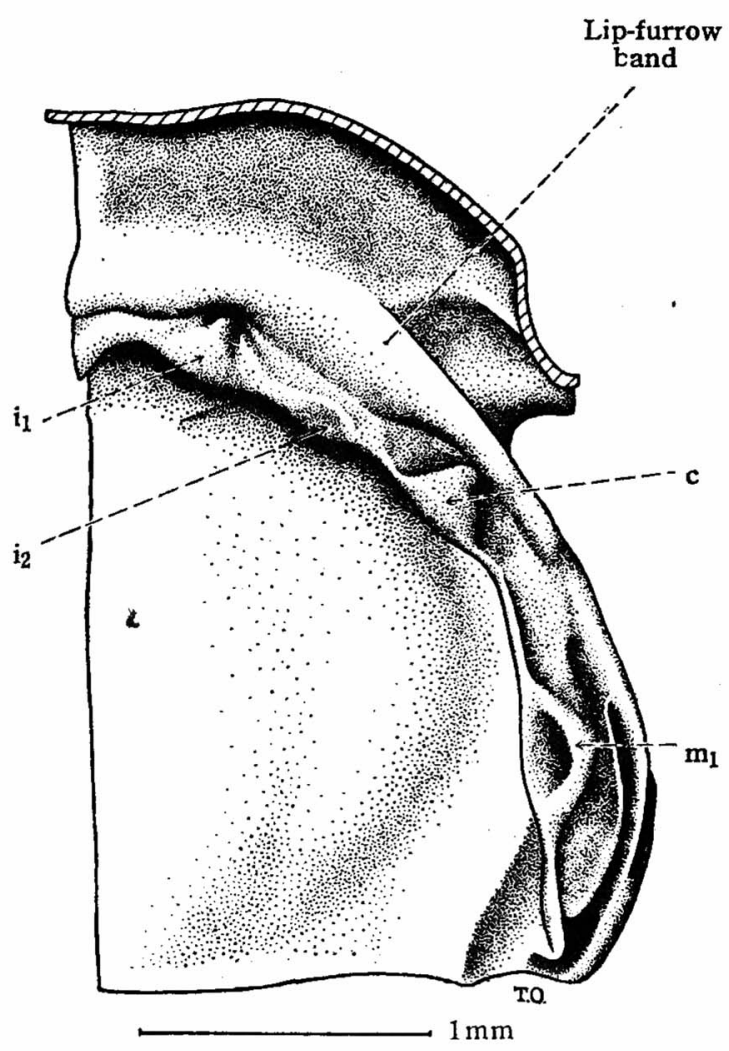

Fig. 15. No. $104(3.6 \mathrm{~cm})$ Reconstruction.

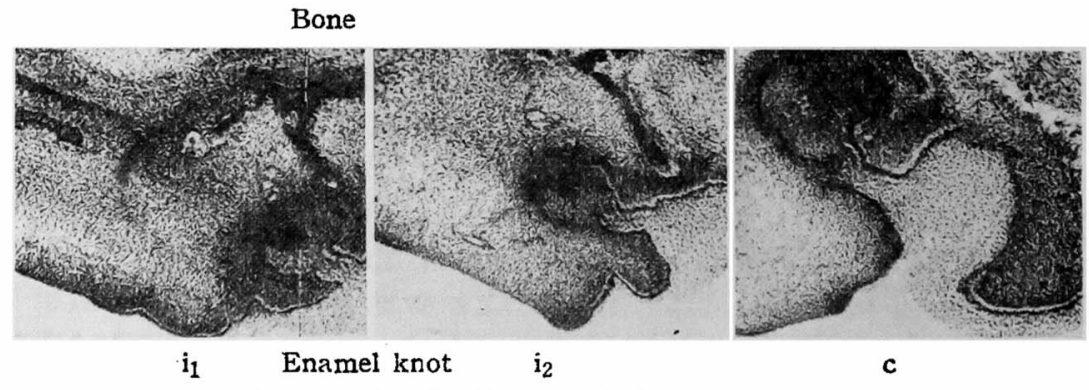

Fig. 16. No. $104(36 \mathrm{~cm})$, Sagittal section. $\times 45$

on the labial side of the germ, which was present only in $i_{1}$ and $c$ in fig. 15 , has begun to develop also in $i_{2}$. The tooth germs are all distinctly carved out from the dental lamina, and from now on we might speak of the enamel organs. This sketch was especially drawn for 


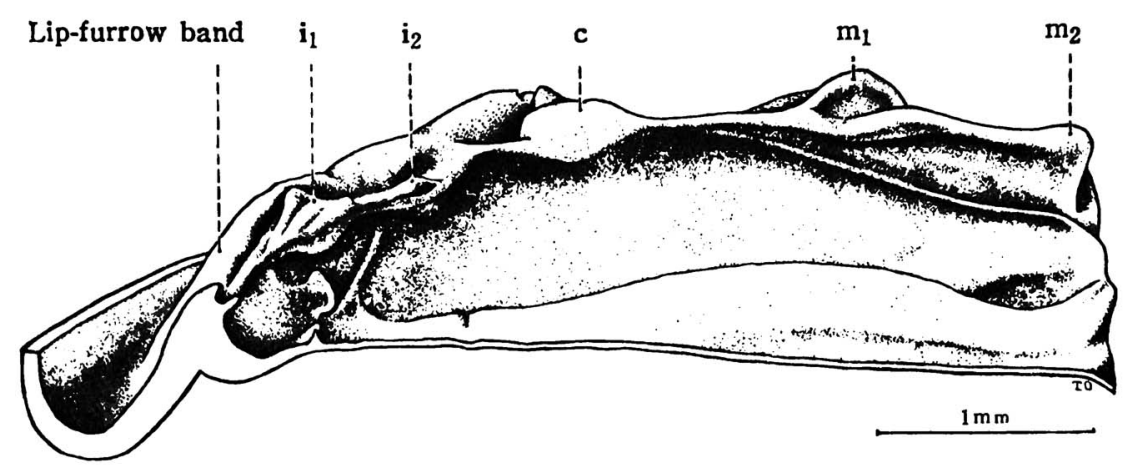

Fig. 17. No. $106(4.8 \mathrm{~cm})$ Reconstruction.

the purpose of demonstrating the different levels of position of the tooth germs. Note the high standing of the canine and the low standing of the lateral incisor. The distance between the centres of the tooth germs is : $i_{1}$ and $i_{2}, 0.6 ; i_{2}$ and $c, 0.92 \mathrm{~mm}$, there being practically no change from the preceding stage.

In the following stage the relative position of the tooth germs is almost the same as the present one. On the distal side of the enamel organs the enamel niche has become visible. In the serial scanning of the horizontal section from the upper side of the jaw, first the canine appears with its enamel organ and at the level where the

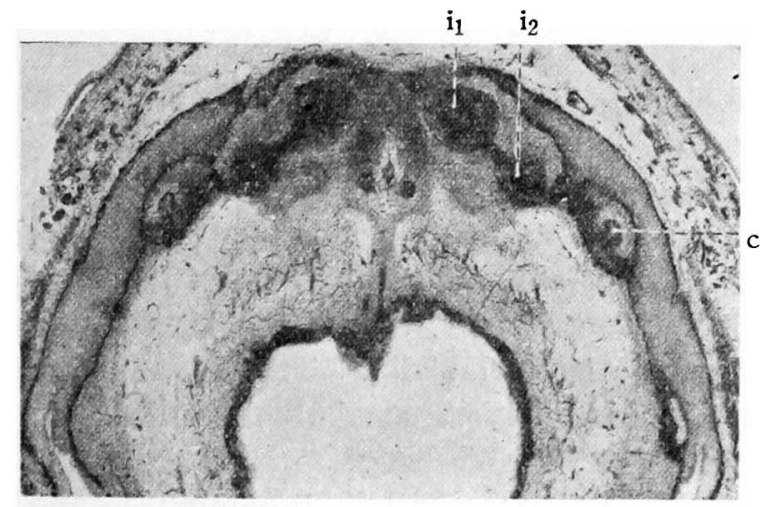

Fig. 18. No. $72(5.3 \mathrm{~cm})$ Horizontal section. $\times$ ca. 14

canine disappears and not before, the lateral incisor begins to appear. Fig. 18 shows the section at this level. The lateral enamel strand of the canine is visible. The lateral incisor is cut approximately in the middle of the enamel organ. The zigzag arrangement of the tooth germs as projected on a horizontal plane can also be seen. 


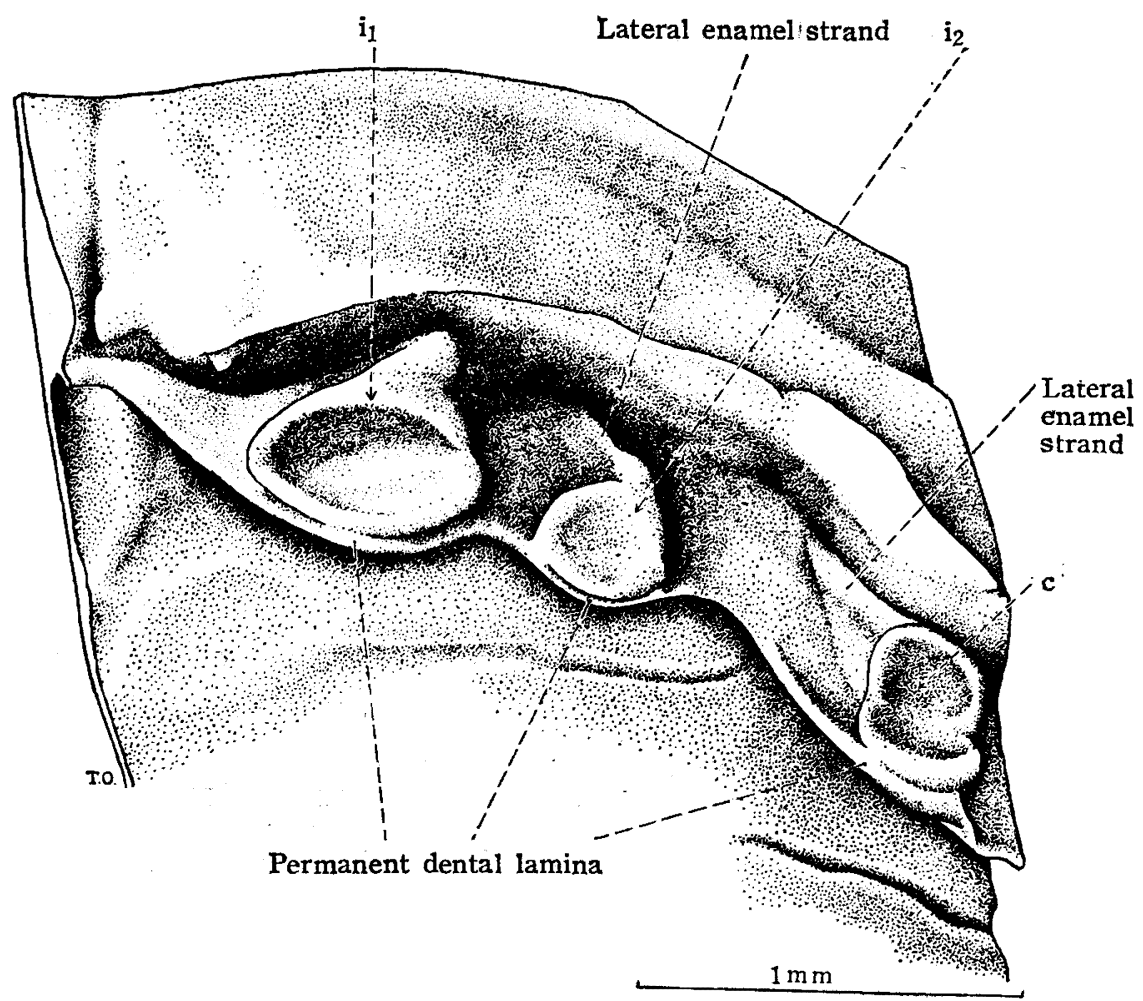

Fig. 19. No. $102(6.9 \mathrm{~cm})$ Reconstruction.

Fig. 19 (No. 102, $6.4 \mathrm{~cm}$ ) and 20 (No. 107, $8.4 \mathrm{~cm}$ ) represent more progressed stages of development. With the exception of the lateral incisor of No. $102(6.4 \mathrm{~cm})$, the permanent dental lamina is isolated, protruding in a wave-form on the palatinal side of the deciduous germs. Although there is enough space in the jaw the germ of the central incisor is situated labially, that of the lateral incisor palatinally, and that of the canine again labially. The canine germ is small but its dental papilla is noticeably directed to the labial side. The canine stands still deeper than the incisor germs. The distance between the germs in embryo No. 102 is: $i_{1}$ and $i_{2}, 0.76 \mathrm{~mm} ; i_{2}$ and c, $1.08 \mathrm{~mm}$, while the corresponding figures in embryo No. 107 are $1.3 \mathrm{~mm}$ and $1.24 \mathrm{~mm}$, respectively. Here we see beginning of a change of the relative position of germs. Up to stage No. 102 (fig. 19) the distance between the central and lateral incisors was smaller than between the lateral incisor and the canine, but in stage No. 107 (fig. 20) the former has surpassed the latter. This is due to the more rapid growth of 


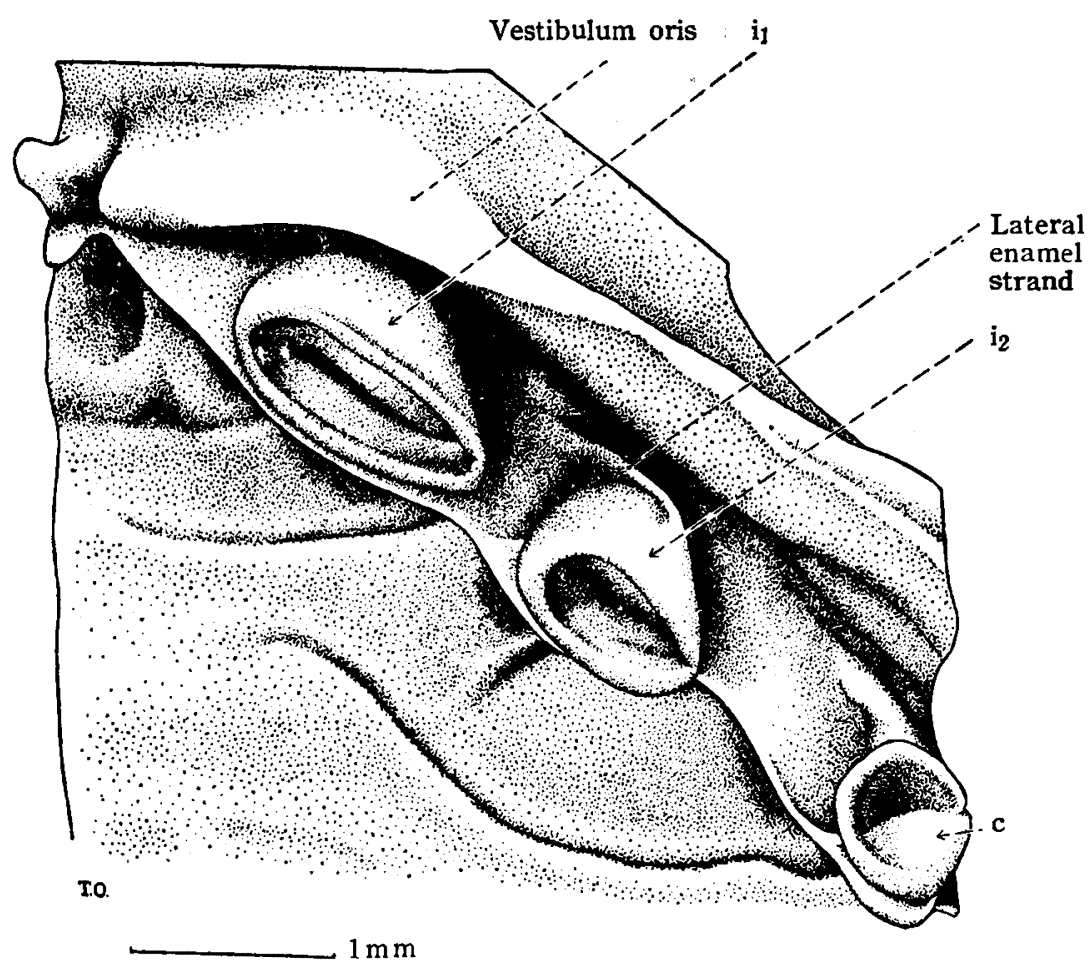

Fig. 20. No. $107(8.4 \mathrm{~cm})$, Reconstruction.

the incisors as compared with that of the canine. So the true interspace between the lateral incisor and the canine is still greater than that between the central and the lateral incisors.

Fig. 21 shows the right front teeth of No. $88(13.0 \mathrm{~cm})$. The germs have grown immensely and both incisors are on top of one another, the lateral being situated palatinally. In the region of the canine there is, however, still some space on the mesial as well as on the distal side of this tooth. In such a condition, the orientation of the enamel organs of the canine is conspicuous. It is so tilted to the labial side that the zigzag arrangement of the tooth germs is quite evident.

Fig. 22 is a horizontal section of the upper jaw of embryo No. 50 $(23.0 \mathrm{~cm})$. Just like fig. 11 for the lower jaw, it illustrates the peculiar zigzag arrangement of the tooth germs in the upper jaw. As compared with the condition in the lower jaw, there is a striking difference in that the mesiodistal diameter of the lateral incisor in the upper jaw almost parallels the curve of the dental arch, while it is rotated 


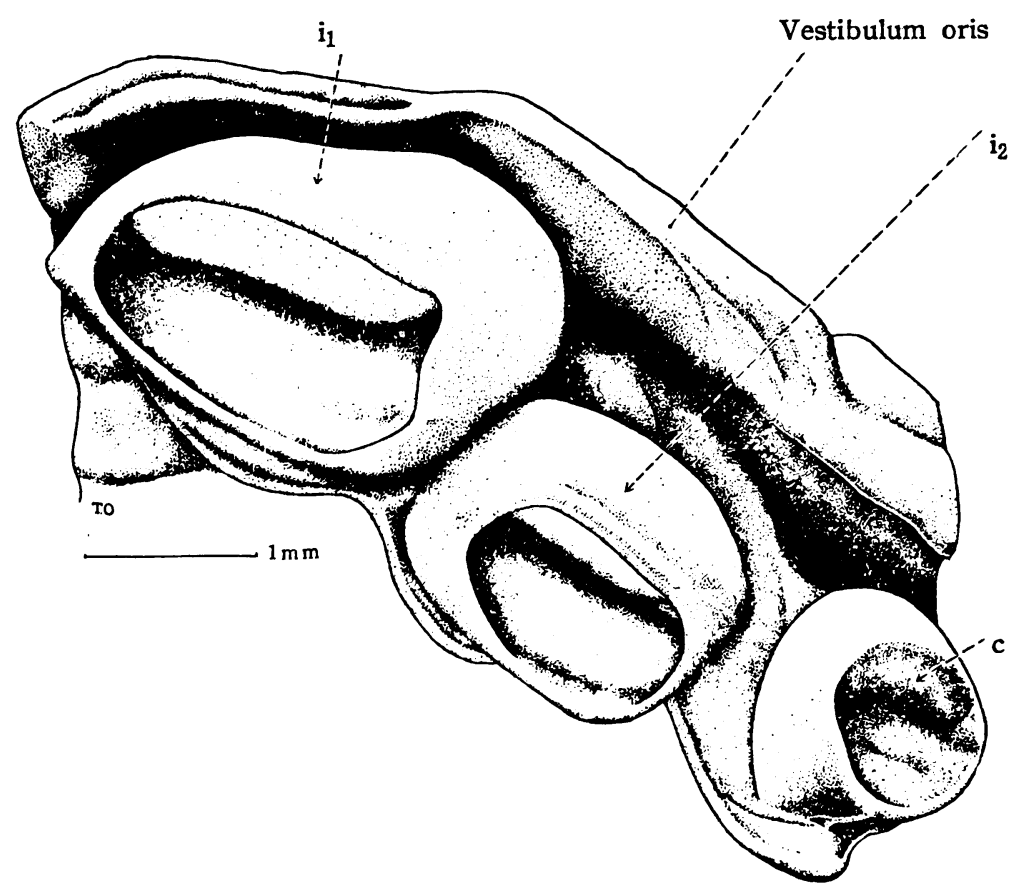

Fig. 21. No. $88(13.0 \mathrm{~cm})$ Reconstruction.

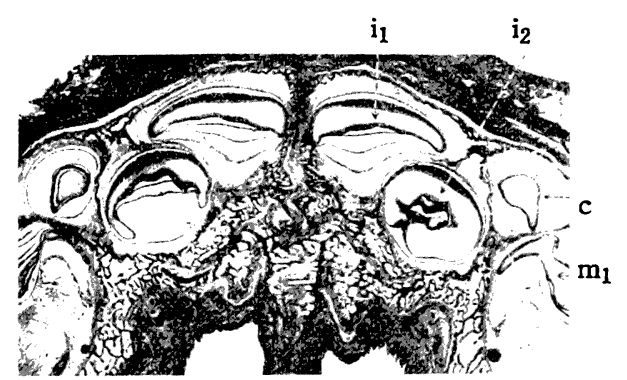

Fig. 22. No. $50(23 \mathrm{~cm})$ Horizontal section. $\times 3$

by ca. $70-80^{\circ}$ in the lower jaw. As regards the cause and mechanism of this rotation, we will discuss in the following chapter.

\section{General observation and discussion}

In the present study I aimed 1) to describe the developmental changes of the position and orientation of the tooth germs in relation to the jaws as well as in reference to each other, and 2) to explain 
the changes from the teleological point of view. Among various kinds of changes which are well illustrated in the sketches of the reconstruction models and photomicrographs of the sections, the following points should especially be taken into consideration:

1) The tooth germs which are formed in a line on the dental lamina are not arranged close to one another, but have an ample interspace between the adjacent two germs. The interspaces are not the same in width in different parts of the dental lamina as well as in the different stages of development. In the lower jaw the interspace is the smallest between the lateral incisor and the canine in the beginning, while in the upper jaw the narrowest interspace is found between the middle and the lateral incisors. The reason for this difference between the jaws as well as why the tooth germs are formed with different distance is not yet clear. Anyway the interspaces gradually diminish and are lost finally because the germs are enlarged more rapidly as the jaws grow. So it should be kept in mind that the tooth germs are quite separated from one another in the early stage of the development and they never interfere with each other in their formation and growth. The crowded condition as is seen in fig. 11 and 22 begins to develop only in the later stage, i.e., in the fifth embryonal month when the calcification of the germs has taken place.

2) Projected on the horizontal plane, the tooth germs are not arranged on a smooth curve of the prospective dental arch. The middle incisor and the canine are protruded to the labial side and on the contrary the lateral incisor and the first premolar are retreated inward, i. e., to the lingual side. So in other words the germs are arranged as it were in a zigzag form. This zigzag arrangement is to some extent already noticeable at the very beginning of the germ formation. However, it becomes more and more distinct as the development progresses. This gradual change of the relative position of the tooth germs is caused mainly through active ingrowth or by selfsteering on the side of the epithelial portion of the dental anlage. The tooth buds do not grow into the mesenchym in the same direction; in the upper jaw the central incisor is directed labialwards, the lateral incisor palatinalwards and the canine again labialwards, while in the lower jaw the central incisor is directed lingualwards, the lateral incisor lingualwards as well as distalwards and the canine, as in the upper jaw, labialwards.

3) The tooth germs are not located on the same level when projected upon the vertical plane, too. The canine is formed originally 
somewhat lower (for the lower jaw) or higher (for the upper jaw, after the formation of a definitive palate) than the germs of other teeth. In later development this difference of level is maintained, a condition caused also through the self-steering of growth by the germs themselves, but not through any passive pressure or pull. The difference is greater in the upper than in the lower jaw, which might be related to the circumstance that the crowding of teeth is on account of the larger size more intensive in the upper than in the lower jaw.

4) Another difference in the position of the tooth germs between the lower and the upper jaw is the rotation of the lateral incisor. Compare here fig. 11 with 22. In these photographs attention should also be paid to the fact that the lateral incisor of the upper jaw are located completely outside the dental arch, while the mesial half of the crown of the lower lateral incisor stands at the level of other teeth. So it might be interpreted in this way: the lower lateral incisor stands halfway in its derailing process and the strong rotation of this tooth is a necessary result of the incomplete extrication from the dental arch. The incomplete extrication of the lateral incisor in the lower jaw might be explained through the inferior size of the lower teeth. Compare the interspace between the lateral incisor and the canine of the upper and the lower. It is by far larger in the lower jaw and is filled up by the mesial portion of the lateral incisor. In the upper jaw there is, however, scarcely any space to accept the part of the crown of the lateral incisor between the middle incisor and the canine.

5) Finally it is our concern to explain the biological significance of the zigzag arrangement of the tooth germs. It should be taken into consideration that the teeth, especially its crown once formed, undergoes no form change; it neither grows nor atrophies (diminishes). On the other hand, the jaws are subjected to a gradual augmentation of dimensions. The zigzag arrangement of the tooth germs seems to me to be an exquisite device of nature for the compensation of the said discrepancy in growth between dentition and the jaw. Thus, through gradual evolution of folding the dental apparatus can always be fitted to the growing jaw bones. This folding of the dental apparatus occurs not only on the horizontal plane but also on the vertical one so that security is maintained in two dimensions.

6) The peculiar arrangement of the tooth germs inside the jaw can sometimes more or less remains long during the adult dentition: for example, the protruded middle incisor and the canine and retreated 
lateral incisor and the milk molars. In addition, the canine can stand high in the upper and low in the lower jaw without reaching the occlusal level. These irregularities in the dental arches are, therefore, not simple crowding of the germs on account of the lack of space in the jaws, but are the natural results of the imperfect evolution of folding, a peculiar arrangement in the dental anlage.

\section{Résumé}

By tracing the developmental changes of the dental anlage and tooth germs in man by means of model reconstruction as well as by serial scanning under microscope, the following points were confirmed:

1) In the early stage of development the tooth germs are separated from one another with ample interspaces so that they can not be influenced in their growth as well as in the development of the position by the neighboring tooth germs (fig. 1, 4, 6, 7, 8, 9, 14, 15, 17, $18,19,20)$.

2) Even at the beginning of development, the tooth germs are not arranged on a smooth line of the future dental arch, but the central incisor and the canine show an indication of labial location, while the lateral incisor is somewhat retreated to the lingual side (fig. $1,2,5,6,7,12,16,17)$. In a similar way, the germs are formed at different levels of the jaws (fig. 2, 5, 6, 12, 16, 17). The dental arch anlage can, therefore, be regarded as the dental arch folding in two dimentions.

3) Tne said folding becomes more distinct as the development proceeds (fig. $7,8,9,18,19,20$ ) so that the tooth germs are arranged in a zigzag-form. This peculiar arrangement is brought forth not through passive pressure or pull from outside, but through the active growth and self-steering of the germs themeselves.

4) From the teleological point of view the zigzag arrangement of the tooth germs has a special purpose in that the development discrepancy between the jaw bones and the tooth can be compensated through the gradual evolution of folding of the dental apparatus. ( $\mathrm{S}$ 'milar investigations in the area of the milk molars as well as in permanent dentition are also necessary to clarify the problem completely. They are already started and the results will be published in the near future.) 


\section{Bibliography}

Ahrens, H., Entwicklung der menschlichen Zähne. Anat. Hefte, Bd. 48, 1913.

Blechschmidt, E., Die Entwicklung der Zahnkeime beim Menschen. Zum Studium der Entwicklungsdynamik der menschlichen Embryonen. Acta anat., 17, 1953.

Blechschmidt, E., Die Entwicklungsbewegungen der Zahnleiste. Roux' Arch. Entw. mech., Bd. 147, 1955.

Bolk, L., Die Ontogenie der Primatenzähne. Odontologische Studiun I. Jena, 1913.

Eidmann, H, Die Entwicklungsgeschichte der Zähne des Menschen. Berlin, 1923.

Lehner, J. u. Plenk, H., Die Zähne. Möllendorff's Handbuch d. mikrosk. Anatomie des Menschen, Bd. V-3, 1936.

Meyer, W., Normale Histologie und Entwicklungsgeschichte der Zähne des Menschen. München, 1951.

Orban, B., Dental Histology and Embryology. Chicago, 1928.

Preuss, F.I., Zur Entwicklungsdynamik der Zahnleiste beim Menschen. Acta anat., 18, 1953.

Röse, C., Ueber die Entwicklung der Zähne des Menschen. Arch. f. mikr. Anat. Bd. 38, 1891.

Wasserfallen, Ph., Les changements de positions des follicules dentaires dans la mandibule du foetus humain. Schweiz. Mschr. Zahnheilk., 64, 1954. 